\title{
Incidência de pacientes queimados atendidos no Hospital de Emergência na cidade de Macapá-AP, durante o ano de 2014
}

Regiane Costa Correa ${ }^{1}$

\footnotetext{
1 Especialista em Fisioterapia Dermato Funcional pelo Centro Universitário Internacional (UNINTER). Graduada em Fisioterapia pela Faculdade Estácio SEAMA. Brasil. E-mail: regianecorreaa@gmail.com
}

RESUMO: As queimaduras são lesões desencadeadas por agentes físicos, químicos, elétricos e térmicos que resultam em níveis variados de perda tecidual de grande a taxa de mortalidade e incapacitação física. Trata-se de um estudo epidemiológico, descritivo, retrospectivo-documental e quantitativo, tendo como fonte de dados, o livro de atendimentos do Centro de Tratamento de Queimados (CTQ) do Hospital Público de Emergência da cidade de Macapá durante o ano de 2014, visando analisar a incidência de pacientes queimados que foram atendidos. Foi constatado o total de 391 atendimentos registrados, sendo 175 (45\%) do sexo feminino e 216 (55\%) do sexo masculino; outro dado verificado foi que, destes, 152 (39\%) eram crianças, 12 (3\%) eram adolescentes, 215 (55\%) eram adultos e 12 (3\%) eram idosos, foi observado que $79 \%$ das ocorrências de queimaduras aconteceram principalmente no ambiente domestico. Conclui-se a necessidade em intensificar programas educativos nas escolas e nos centros comunitários em meios de comunicação, ampliar o atendimento para outras unidades de saúde, melhorar as condições físicas do atendimento, e preencher as lacunas nos registros dos pacientes atendidos no CTQ.

Palavras-chave: Queimaduras. Pacientes. Hospital de Emergência.

Incidence of burn patients, treated in the Emergency Hospital in the city of Macapá-AP, during the year 2014

ABSTRACT: Burns are injuries triggered by physical, chemical, electrical and thermal agents that result in varying levels of tissue loss of high mortality rate and physical disability. It is an epidemiological study, descriptive, retrospective and documentary and quantitative, with the data source, the book calls the Burn Treatment Center (CTQ) of the public hospital emergency in the city of Macapá during the year 2014, aiming to analyze the incidence of burn patients who were treated. Was I note the total of 391 registered calls, with 175 (45\%) were female and 216 (55\%) were male, other data found was that these $152(39 \%)$ were children, $12(3 \%)$ were adolescents, 215 (55\%) are adults and 12 (3\%) are seniors, it was observed that $79 \%$ of cases of burns occurred mainly in the domestic environment. The conclusion is the need to intensify educational programs in schools and community centers of communication, expand the service to other health, improve the physical conditions of service, and fill the gaps in the records of patients treated in CQT.

Keywords: Burns. Patients. Emergency Hospital. 


\section{INTRODUÇÃO}

Queimaduras são lesões dos tecidos orgânicos decorrentes de trauma de origem térmica resultante da exposição ou contato com chamas, líquidos quentes, superfícies quentes, eletricidade, frio, substâncias químicas, radiação, atrito ou friç̧ão (AMARAL et al. 2008). As lesões por queimaduras são consideradas mundialmente como um dos principais problemas de saúde pública, sendo significativamente elevados os índices de mortalidade. Quando não levam a óbito, dependendo da gravidade e do nível de comprometimento, podem ocasionar sequelas graves, que vão desde limitações funcionais, desordem psicológica e social. Dados da Sociedade Brasileira de Queimaduras demonstram que, anualmente, ocorrem cerca de um milhão de acidentes por queimaduras no Brasil, dos quais apenas 200 (duzentos) mil pacientes buscam assistência hospitalar e 40 (quarenta) mil demandam hospitalização (ANDRADE; MARTINS, 2007; COLLET et al., 2012; DUTRA; LONIEN; PEREIRA, 2010; BENTES; MEIJA, 2012; VALE, 2005).

Apesar dos avanços da medicina no tratamento das queimaduras com o uso de enxertia e novas técnicas de curativos, as taxas de mortalidade ainda são grandes devido às complicações como infecções, sepse e desnutrição. Sabe-se que os pacientes queimados requerem uma atenção multiprofissional, além de atendimento especializado.

O presente trabalho propõe-se conhecer as taxas e o perfil dos pacientes que foram atendidos no Centro de Tratamento de Queimados do Hospital de Emergência da cidade de Macapá no ano de 2014, a fim de propor políticas públicas de melhorias na rede estadual de saúde e consequentemente, proporcionar um atendimento de qualidade para os pacientes sequelados por essas deformidades.

O trabalho está estruturado da seguinte forma: a seguir é feita uma breve revisão de literatura associada com a temática explorada. Nos tópicos subsequentes apresentam-se os métodos adotados e os consequentes resultados da pesquisa. Por fim, far-se-á as considerações finais.

\section{AVALIAÇÃO DE RISCO E A GRAVIDADE DA QUEIMADURA}

Collet et al. (2012) afirmam que são muitos os fatores envolvidos nas queimaduras que devem ser observados durante a avaliação do paciente, como o agente causador, a profundidade, extensão, área queimada, idade da vítima, sexo, existência de doenças prévias e a concomitância de condições agravantes, além da área corporal total, o comprometimento de todas as camadas de pele e tecidos profundos, a inalação de fumaça e produtos tóxicos, idade abaixo de 30 anos e acima de 60 anos são preditivos de aumento na mortalidade. Em relação ao sexo, deve-se atentar que entre a faixa de 30 a 59 anos, a mortalidade na mulher é duas vezes maior, apesar de todo avanço no diagnóstico, tratamento e aumento na sobrevida do paciente jovem, no paciente acima de 75 anos, não há melhora na expectativa de sobrevida (LIMA; LIMAVERDE, 2006).

\section{FISIOPATOLOGIA}

As queimaduras comprometem a integridade funcional da pele, quebrando a homeostase hidroeletrolítica e alterando o 
controle da temperatura interna, flexibilidade e lubrificação da superfície corporal. O comprometimento da pele ocorre em virtude da extensão e profundidade das lesões (ROCHA, 2009).

De acordo com Bentes e Meija (2012), o paciente queimado apresenta alterações fisiopatológicas importantes como hipóxia tecidual, ativação de todas as vias biológicas da inflamação, alteração da imunidade celular, da imunidade mediada por citocinas, fatores de crescimento, do sistema complemento, da casca de coagulação, lesão de reperfusão e disfunção endotelial.

\section{DETERMINAÇÃO DO GRAU DE QUEIMA- DURA}

Segundo Bentes e Meija (2012), nos últimos anos, uma gama de estudos tem demonstrado diferentes alterações fisiopatológicas que ocorrem nas queimaduras, afirmam que a pele humana pode tolerar sem prejuízo, temperaturas de até $44^{\circ} \mathrm{C}$; acima deste valor ocorrem diferentes lesões que são classificadas dependendo do seu grau.

As queimaduras são classificadas de acordo com a extensão da superfície corpórea queimada, o fator determinante do resultado estético e funcional da queimadura é calculado em porcentagem da área total queimada. Além da área queimada, deve-se observar a temperatura, profundidade da queimadura, tempo de exposição, intensidade do agente gerador ou transmissor de calor, podendo ser de primeiro (Quadro 1), segundo (Quadro 2) ou terceiro grau (Quadro 3). Há casos em que a queimadura, além da derme e epiderme, atinge a fáscia, músculos, tendões, articulações, ossos e cavidades, são gravíssimas e recebem de- nominação de 40 grau (VALES, 2005; LIMA; LIMAVERDE, 2006).

Quadro 1 - Classificação das queimaduras de primeiro grau segundo a profundidade.

Frame 1 - Classification of first-degree burns according to depth.

\begin{tabular}{|l|}
\hline \multicolumn{1}{|c|}{ Primeiro grau } \\
\hline Compromete apenas a epiderme. \\
Apresenta eritema, calor e rubor. \\
Não há formação de bolhas. \\
Evolui com descamação há poucos dias. \\
Regride sem deixar cicatrizes. \\
Não é considerada na avaliação da área atingida. \\
Repercussão sistêmica e desprezível. \\
\hline
\end{tabular}

Quadro 2 - Classificação das queimaduras de segundo grau segundo a profundidade.

Frame 2 - Classification of second degree burns according to depth.

\begin{tabular}{|l|}
\hline \multicolumn{1}{|c|}{ Segundo grau } \\
\hline Compromete totalmente a epiderme e parcialmente \\
a derme. \\
Apresenta dor, eritema, bolhas, erosão ou ulceração. \\
Há regeneração espontânea. \\
Ocorre reepitelização a partir dos anexos cutâneos \\
(folículos pilosos e glândulas). \\
Cicatrização mais lenta. \\
Discromias, cicatrizes. \\
\hline
\end{tabular}

Quadro 3 - Classificação das queimaduras de terceiro grau segundo a profundidade.

Frame $\mathbf{3}$ - Classification of third degree burns second depth.

\begin{tabular}{|l|}
\hline \multicolumn{1}{|c|}{ Terceiro grau } \\
\hline Atinge camada subcutânea, tendões, ligamentos, \\
músculos e ossos. \\
Lesão branca ou marrom, seca, dura e inelástica. \\
Não há regeneração espontânea, necessita de enxer- \\
tia. \\
Eventualmente pode cicatrizar, com retração das \\
bordas. \\
\hline
\end{tabular}

\section{EXTENSÃO}

Os riscos gerais do paciente queimado nas primeiras horas dependem fundamentalmente da extensão da área queimada. A repercussão sistêmica é maior devido à perda das funções da pele. Quanto maior a 
área afetada, sua extensão é calculada em porcentagem da superfície total (SC), sendo consideradas apenas as áreas queimadas com profundidade de segundo e terceiro graus.

O método mais usado é a regra dos noves, ou de Wallace, onde o corpo é dividido em segmentos valendo $9 \%$ de sua superfície ou múltiplos deste. Este método é pratico e rápido muito utilizado no primeiro atendimento, foi proposto para adultos, no qual o esquema propõe o valor de $9 \%$ para a cabeça e $9 \%$ para cada membro superior; $18 \%$ para o tronco posterior, $18 \%$ para o tronco anterior e $18 \%$ para cada membro inferior; $1 \%$ para o pescoço (Quadro 4). Convém avaliar que entre o adulto e a criança, existe uma significante diferença no cálculo da área corporal queimada, devendo ser modificada a regra dos nove para a "Regra dos Onze" (Quadro 5), esse método é ajustado para crianças até 10 anos de idade (CANTINHO; DIEGO, 2006; LIMA; LIMAVERDE, 2006; ROCHA, 2009; VALE, 2005).

Quadro 4 - Regra dos noves (Wallace), para cálculo da superfície queimada em adultos e crianças a partir de 10 anos de idade.

Frame 4 - Rule of nines (Wallace), to calculate the burned surface in adults and children from 10 years old.

\begin{tabular}{|lc|}
\hline Segmento corporal & Porcentagem (SC) \\
Cabeça e pescoço & 9 \\
Cada membro superior & $9(x 2)$ \\
Cada quadrante do tronco & $9(x 4)$ \\
Cada coxa & $9(x 2)$ \\
Cada perna e pé & $9(x 2)$ \\
Genitais e períneo & 1 \\
Total & 100 \\
\hline
\end{tabular}

SC: superfície corporal total.

Quadro 5 - Regra dos Onze (Wallace), para cálculo da superfície queimada em crianças até 10 anos de idade Frame 5 - Rule Eleven (Wallace), to calculate the burned surface in children up to 10 years old.

\begin{tabular}{|ll|}
\hline Cabeça e face & $11 \%$ \\
\hline Membros superiores & $11 \%$ \\
\hline
\end{tabular}

\begin{tabular}{|ll|}
\hline Membros inferiores & $11 \%$ \\
\hline Tronco em cada lado & $11 \%$ \\
\hline
\end{tabular}

O esquema de Lound e Browder (Tabela 1) embora concebido a mais de meio século, é mundialmente aplicado, consiste em avaliar as proporções do corpo atingidas em relação à idade, ao se preencher a tabela modificada deve-se assinalar o valor de cada região atingida, variando de acordo com a idade. Avalia-se a superfície e o grau de profundidade, o que permite calcular com exatidão o subtotal de queimaduras de 20 e 3o grau e o valor total de superfície corporal queimada (DUTRA; LONIEN; PEREIRA, 2010; CANTINHO; DIEGO, 2006).

Tabela 1 - Esquema de Lound e Browder.

Table 1 - Scheme Lound and Browder.

\begin{tabular}{|c|c|c|c|c|c|c|c|}
\hline IDADE (anos) & 1 & 1-4 & $5-9$ & $10-14$ & $\begin{array}{c}\text { Adul- } \\
\text { to }\end{array}$ & \begin{tabular}{l|}
20 \\
grau
\end{tabular} & $\begin{array}{c}\text { 3o } \\
\text { grau }\end{array}$ \\
\hline Cabeça & 19 & 17 & 13 & 11 & 7 & & \\
\hline Pescoço & 2 & 2 & 2 & 2 & 2 & & \\
\hline Tronco anterior & 13 & 13 & 13 & 13 & 13 & & \\
\hline Tronco posterior & 13 & 13 & 13 & 13 & 13 & & \\
\hline Braço direito & 4 & 4 & 4 & 4 & 4 & & \\
\hline Braço esquerdo & 4 & 4 & 4 & 4 & 4 & & \\
\hline Antebraço direito & 3 & 3 & 3 & 3 & 3 & & \\
\hline Antebraço esquerdo & 3 & 3 & 3 & 3 & 3 & & \\
\hline Mão direita & 2,5 & 2,5 & 2,5 & 2,5 & 2,5 & & \\
\hline Mão esquerda & 2,5 & 2,5 & 2,5 & 2,5 & 2,5 & & \\
\hline Nádega direita & 2,5 & 2,5 & 2,5 & 2,5 & 2,5 & & \\
\hline Nádega esquerda & 2,5 & 2,5 & 2,5 & 2,5 & 2,5 & & \\
\hline Genitália & 1 & 1 & 1 & 1 & 1 & & \\
\hline Coxa direita & 5,5 & 6,5 & 8 & 8,5 & 9,5 & & \\
\hline Perna direita & 5 & 5 & 5,5 & 6 & 7 & & \\
\hline Perna esquerda & 5 & 5 & 5,5 & 6 & 7 & & \\
\hline Pé direito & 3,5 & 3,5 & 3,5 & 3,5 & 3,5 & & \\
\hline Pé esquerdo & 3,5 & 3,5 & 3,5 & 3,5 & 3,5 & & \\
\hline \multicolumn{6}{|c|}{ Total Parcial da Área Queimada } & & \\
\hline Total Geral da Área & & & & & & & \\
\hline
\end{tabular}

Fonte: Cantinho e Diego (2006).

\section{METODOLOGIA}

A pesquisa será de caráter epidemiológico, descritivo, retrospectivo-documental e quantitativo, tendo como fonte de dados os registros no livro de atendimentos do Centro de Tratamento de Queimados (CTQ) do 
Hospital Público de Emergência da cidade de Macapá durante todo o ano de 2014. Ressalta-se que o CTQ é, atualmente, o único local que recebe os pacientes com queimaduras de media e alta complexidade à nível estadual.

O CTQ do Hospital de Emergências de Macapá é composto por uma pequena área de enfermaria com quatro leitos, unidade de Terapia Intensiva com três leitos, banheiro e recepção. $O$ funcionamento é ininterrupto e dispõem de uma equipe com dois enfermeiros, três técnicos de enfermagem, um fisioterapeuta e dois médicos cirurgiões plásticos, que atendem em regime de plantões intercalados. Durante a pesquisa, foram feitas visitas ao enfermeiro responsável pelo livro de registros e ao médico cirurgião, coordenador do CTQ, os quais disponibilizaram a única fonte de arquivo: o livro de registro, onde constam as informações relacionadas aos atendimentos da unidade.

No livro de registros do CTQ foram registrados 391 atendimentos no ano de 2014, os quais foram tabulados no programa Microsoft Excel de forma descritiva e expostos na forma de gráficos com as seguintes variáveis disponibilizadas no livro e de acesso público, sem necessidade de autorização documental do comitê de ética: total de atendimentos, permanência, sexo, idade, agente causador, tipo de acidente, grau de queimadura, área atingida e óbitos, tais dados foram coletados e tabulados no mês de março de 2015 durante as visitas realizadas no CTQ.

\section{RESULTADOS E DISCUSSÕES}

Segundo Albuquerque et al. (2010), as lesões ocasionadas por queimaduras são a urgência médica que mais desencadeiam problemas físicos, financeiros e psicológicos para os pacientes. Os efeitos das grandes queimaduras geralmente são irreparáveis.

A distribuição dos sexos dos pacientes varia conforme o local estudado, porém, no Brasil, observou-se que mais de $60 \%$ das queimaduras ocorrem em homens, corroborando com os dados obtidos na pesquisa (ANDRADE; MARTINS, 2007), que envolveu 391 pacientes queimados, que foram atendidos no CTQ do Hospital de emergência durante o ano de 2014, sendo 175 (45\%) do sexo feminino e 216 (55\%) do sexo masculino, sobre a faixa etária de idade foi verificado que do total de atendimentos, 152 (39\%) foram crianças, 12 (3\%) foram adolescentes, 215 (55\%) foram adultos e 12 (3\%) foram idosos, sendo tais dados ilustrados no Gráfico 1, a seguir:

Gráfico 1 - Distribuição dos dados segundo a idade e o sexo Graphic 1 - Data distribution according to age and sex

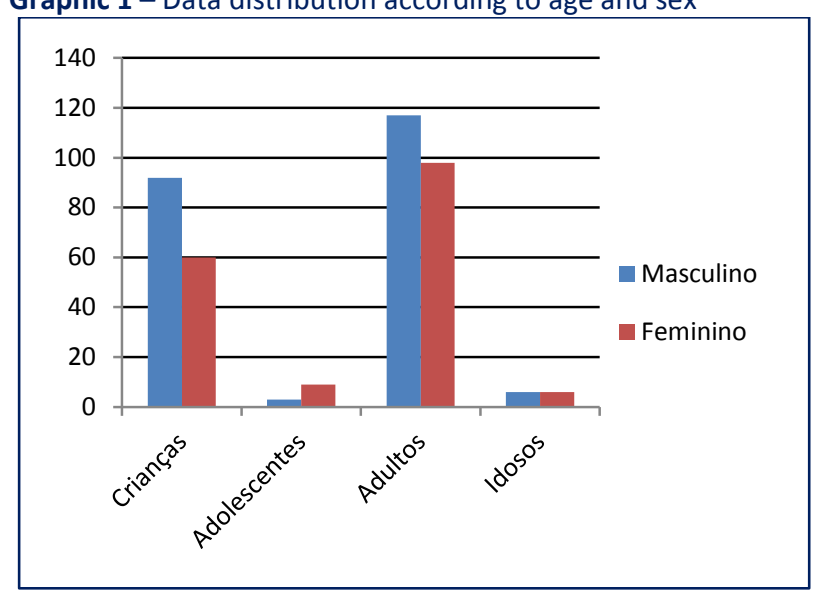

Fonte: Pesquisa de campo

A estrutura e o acesso dos serviços oferecidos nas cidades interioranas, não proporcionam uma assistência direcionada para os pacientes queimados, sendo assim buscam-se atendimento especializado no CTQ, cujo espaço reúne todas as condições materiais, físicas e humanas necessárias à 
vítima de queimadura. A busca por este serviço sistematizado ocasiona demanda e sobrecarga, comprometendo ainda mais a efetividade e qualidade do serviço ofertado no único CTQ dentro do ambiente hospitalar de emergência na cidade de Macapá.

Existe a necessidade de disseminar o atendimento aos pacientes vítimas de queimaduras de baixa gravidade entre as unidades de pronto atendimento (UPA) e unidades básicas de saúde (UBS). Assim, os casos de maior gravidade, como a queimadura de 3o grau e suas severas consequências, seriam atendidos na unidade emergencial. Para isto acontecer, é importante a tomada de ações mais efetivas e de acompanhamento a esses pacientes.

As autoridades responsáveis precisam conhecer a realidade e as necessidades dos serviços, a partir das experiências das pessoas que recebem assistência nos mesmos, bem como dos profissionais que ali assistem, assim evidencia-se a importância da humanização da assistência nos serviços de saúde, mas para tanto, é necessário o planejamento de um centro de queimados de porte, de todo um moderno aparato técnico-científico que o sustente e, acima de tudo, de uma equipe multidisciplinar (DUTRA; LONIEN; PEREIRA, 2010).

É indispensável o envolvimento de todos os profissionais de saúde, cada qual conhecendo o seu papel e sua importância, aliado ao reconhecimento das necessidades, tanto do paciente quanto de seus familiares, já que a família é a principal fonte de apoio destes pacientes (ASSIS, 2010; COLLET et al., 2012).

Os profissionais de diferentes áreas do conhecimento, no âmbito da atenção primaria, podem também contribuir orientando os pais, responsáveis e a própria criança para os riscos ambientais que os rodeiam e assim ter subsídios para evitá-los (COLLET et al., 2012).

Os perigos estão presentes em várias partes das residências, estando a cozinha entre os ambientes mais citados. Uma das maneiras efetivas de promover a prevenção de acidentes infantis consiste na participação direta da família e da escola enquanto responsáveis pela formação das crianças e dos adolescentes, assim sendo, as abordagens e comportamentos preventivos devem ser iniciados no âmbito familiar e ser extensivos ao contexto escolar.

Considerar a cultura, os costumes e as crenças familiares, constituem fatores essenciais para a implementação do cuidado e prevenção de novos acidentes domésticos. Estes, na maioria das vezes, são potencializados pela inobservância, pelos hábitos de vida e pela ausência de um comportamento preventivo por parte das famílias.

O conhecimento dos acidentes com queimaduras entre crianças e adolescentes deve estar pautado numa ótica cultural e familiar a fim de que seja valorizado por elas não apenas a cura da doença, mas a prevenção de novos acidentes.

Observando os atendimentos no ano de 2014, a grande maioria são pacientes vítimas de acidentes domésticos, normalmente apresentando 1 으 e 20 grau de queimaduras. Destes pacientes, $7 \%$ vieram de áreas rurais, e $58 \%$ procuraram o hospital de emergência pela existência de apenas esta unidade de pronto atendimento para pacientes queimados em Macapá, porém em crítico funcionamento. Isto justifica a grande procura por atendimento no centro de Terapia em Queimados (CTQ) nas capitais brasileiras (COLLET et al., 2012), a maior preocupação da equipe médica do CTQ de Macapá, é 
com os pacientes com lesões de queimaduras em articulações, mas o processo de recuperação de pacientes que se submeteram ou não ao tratamento cirúrgico é executado pela equipe, a fim de proporcionar o retorno do paciente a uma vida produtiva.

Em relação às ocorrências mensais de queimadura no referido ano de 2014 no Hospital de Emergência, foi constatado que os acidentes aconteceram durante todos os meses com poucas variações, porém o mês de junho obteve o maior índice de atendimentos registrados no CTQ, assim como observado por Collet et al. (2012). Possivelmente estejam relacionados com as festividades juninas, comemoradas com grande intensidade nesta época com o manuseio inadequado de fogos de artifício e brincadeiras em fogueiras, estes praticados não por apenas por adultos, mas principalmente por crianças, elevando os riscos de acidentes

Quanto ao agente causador de queimaduras, Civile e Finotti (2012) e Alburquerque et al. (2010) afirmaram em seus estudos que, das maiores causas de acidentes que levam à queimadura, $75 \%$ ocorrem dentro de ambientes domésticos ou exercendo sua profissão no setor de serviços como cozinheira. Desta forma, tal pesquisa evidenciou que $79 \%$ dos acidentes com queimaduras, são domésticos, isso se deve à utilização direta de fogo para cozinhar e do uso de álcool como produto de limpeza, segundo o CTQ além do manuseio de grandes quantidades de combustível, como o acidente que aconteceu na zona sul de Macapá, em quem um barco explodiu com 3,5 mil litros de gasolina. Eles ainda afirmam que os eventos desencadeados por eletricidade e por substancias químicas são frequentes, contudo em virtude da agressivi- dade destes agentes, são sempre consideradas as mais graves.

Bueno et al. (2008) revelam que os idosos também são passiveis de maiores risco de morbidade e mortalidade decorrente das complicações inerente a queimadura como as infecções e as sequelas, por ocorrerem, em sua maioria, na supervisão de um adulto, $11 \%$ dos pacientes sofreram acidente de trabalho, e $10 \%$ foram vítimas de queimaduras provocadas por acidente de trânsito, descarga de moto, sendo a maioria, adultos do sexo masculino, como mostra o Gráfico 2 exemplificado:

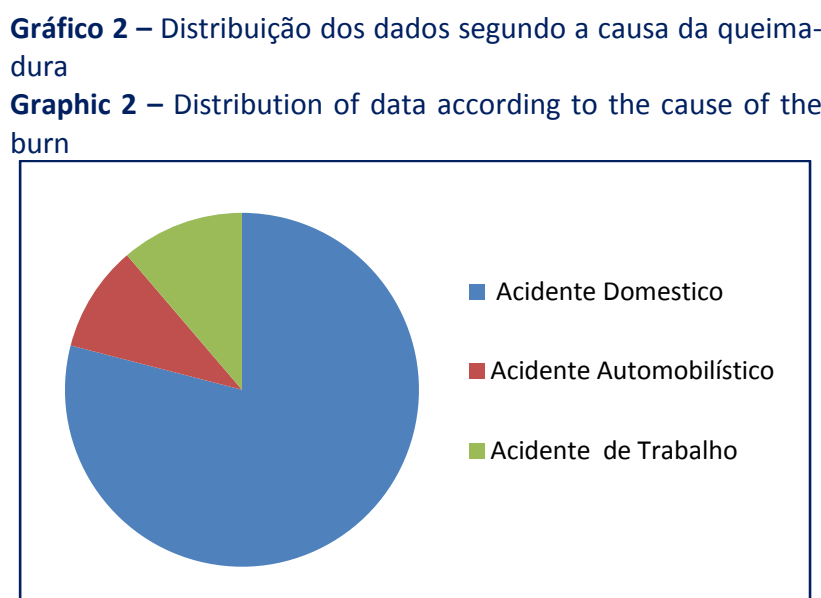

Fonte: Pesquisa de campo

Nesta pesquisa foram considerados adolescentes os indivíduos entre 17 e 19 anos, e idosos, maiores de 60 anos. Foi observado o alto índice de acidentes domésticos envolvendo crianças de 0 a 4 anos, pois ainda é a faixa etária com maior número de ocorrências de queimaduras, segundo o CTQ, justificando a falta de vigilância adequada e a necessidade de conscientização de pais e comunidades.

O número de pessoas vítimas de queimaduras, em 2014, foi de 391. Segundo o CTQ, no ano anterior foi de 494 atendimentos registrados, a previsão para 2015 é que 
reduza a taxa de acidentes de queimaduras. Os pacientes mais graves, ou seja, queimaduras de 3 o recuperaram as habilidades da vida diária mais rapidamente, quando a reabilitação é determinada no inicio do tratamento, os demais foram vítimas de queimaduras por 1ㅇ e 20 grau e a média de permanência do CTQ foi de 1 a 3 dias.

Os queimados apresentaram um ou dois tipos de graus de queimaduras, as mais frequentes foram de 10 e 2o grau, os pacientes que tiveram queimadura de 3 o grau, foram acometidos de um maior número de sequelas estéticas e funcionais. Assis (2010) observou que os avanços no atendimento hospitalar de queimaduras têm contribuído para a sobrevivência de pacientes que sofreram trauma térmico, o que tem favorecido na redução da taxa de mortalidade entre as vítimas de lesões de queimaduras, contudo muitas pessoas ainda ficam sequeladas e morrem a cada ano por causa da queimadura, assim como nesta pesquisa, apenas 04 (1\%) foram a óbito, mediante este resultado, acredita-se que a assistência precoce, possa ter contribuído de forma positiva para a redução do número de mortes, melhora das condições de vida e recuperação dos pacientes acometidos por queimaduras (COLLET et al., 2012).

Segundo o CTQ, hoje em dia na capital, os sistemas de resgate, como os enfermeiros e o Serviço Móvel de Atendimento de Urgência (SAMU), estão mais capacitados para garantir o menor risco possível de lesão no transporte do local do acidente até o centro de tratamento, os pacientes com queimaduras e sequelas mais graves foram submetidos à intervenção cirúrgica de autoenxertia, a fim de otimizar o processo cicatricial, não foi possível aprofundar as informações sobre tais procedimentos ci- rúrgicos, uma vez que esta variável não consta dentre os registros contidos no livro.

Observando através dos dados desta pesquisa, os seguintes segmentos corporais: os membros superiores foram alvos de maior comprometimento pelas queimaduras, atingindo $89 \%$ dos pacientes, geralmente associado com outras regiões, os membros inferiores aparecem em segundo lugar, atingindo $70 \%$ dos pacientes também associado com outras áreas, o tórax e a face associados ou não com outros segmentos, surgem em terceiro lugar significando 30\% do total de pacientes, os resultados apontaram os mesmos relatados por Andrade $\mathrm{e}$ Martins (2007).

Um dado que chamou a atenção nesta pesquisa é que, parte significativa das informações precisas não continha no livro de registros, sendo o único acervo de informações que o CTQ do único Hospital de Emergência da cidade de Macapá contém, inviabilizando uma análise mais aprofundada, comprometendo as informações e análises reais sobre determinados eventos, esta ausência foi a mesma barreira encontrada na pesquisa de Collet et al. (2012). Como foi constatado nos registros, quanto à natureza dos acidentes, a maioria é evitável.

Identificaram-se ainda lacunas nos registros, ou seja, "incompletude" de alguns dados importantes para análise do perfil clínico-epidemiológico das vítimas de queimaduras, salientando-se a necessidade de pesquisas acerca dos obstáculos impeditivos para que o registro seja adequado, e de forma mais detalhada, no momento do atendimento pelos profissionais de saúde, os registros devem ser realizados com responsabilidade e compromisso, pois representa a comunicação escrita na interligação entre os serviços, ou seja, podem expressar a in- 
cidência, prevalência de determinados agravos e o perfil da assistência, sendo também, material de referência para o ensino e novas pesquisas, no âmbito da saúde pública.

\section{REFERÊNCIAS}

ALBUQUERQUE, M. L. L.; et al. Análise dos pacientes queimados com sequelas motoras em um hospital de referência na cidade de Fortaleza - CE. Revista Brasileira de Queimaduras, v. 9, n. 3, p. 89-94, 2010.

AMARAL, C. E. R.; et al. Queimaduras: diagnóstico e tratamento inicial. Sociedade Brasileira de Cirurgia Plástica, 2008.

ANDRADE, S. M.; MARTINS, C. B. G. Queimaduras em crianças e adolescentes: análise da morbidade hospitalar e mortalidade. Paraná, 2007.

ASSIS, J. T. S. J. Conhecendo a vida ocupacional do paciente queimado por autoagressão após a alta hospitalar. Universidade de São Paulo, 2010.

BENTES, A. N.; MEIJA, D. P. M. Recursos fisioterapêuticos utilizados no tratamento das cicatrizes hipertróficas em pacientes queimados, 2012.

BUENO, R. F.; et al. Perfil epidemiológico das crianças internadas por queimaduras no hospital Universitário evangélico de Curitiba (HUEC) no período de julho de 2007 a Fevereiro de 2008.

CANTINHO, F. A. F.; DIEGO, L. A. S. Fisiopatologia do grande queimado. Rio de Janeiro, 2006.

CIVILE, V. T.; FINOTTI, C. S. Abordagem fisioterapêutica precoce em pacientes críticos queimados. Revista Brasileira de Queimaduras, v. 2, p. 85-88, 2012.

COLLET, N.; et al. Queimaduras em crianças e adolescentes: caracterização clínica e epi- demiológica. Revista Gaúcha de Enfermagem, v. 33, n. 4, p. 133-141, 2012.

DUTRA, F. C.; LONIEN, S. C. H.; PEREIRA, E. M. C. P. O paciente queimado e a cicatrização: uma revisão literária. Londrina, 2010. LIMA, O. S.; LIMAVERDE, F. S. Queimados: alterações metabólicas, fisiopatologia, classificação e interseções com o tempo de jejum. Fortaleza, 2006

ROCHA, C. L. J. V. Histofisiologia e classificação das queimaduras: consequências locais e sistêmicas das perdas teciduais em pacientes queimados. Revista Interdisciplinar de Estudos Experimentais, Rio de Janeiro, v. 1, n. 3, p. 140-147, 2009.

VALE, E. C. S. Atendimento em queimaduras: a abordagem do dermatologista. Inicial management of burns: approach bydermatologists, 2005.

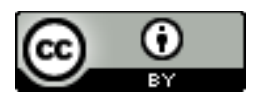

License information: This is an openaccess article distributed under the terms of the Creative Commons Attribution License, which permits unrestricted use, distribution, and reproduction in any medium, provided the original work is properly cited.

Artigo recebido em 05 de janeiro de 2016.

Avaliado em 08 de março de 2016.

Aceito em 24 de maio de 2016.

Publicado em 25 de maio de 2016.

Como citar este artigo (ABNT):

CORREA, Regiane Costa. Incidência de pacientes queimados atendidos no Hospital de Emergência na cidade de Macapá-AP, durante o ano de 2014. Estação Científica (UNIFAP), Macapá, v. 6, n. 1, p. 53-61, jan./abr. 2016. 